\title{
CD79a, CD56 ve CD5 ko-ekspresyonu gösteren ve bifenotipik lösemi ile karışan AML M1'li çocuk olgu
}

\author{
A child AML-M1 with CD79a, CD56, and CD5 coexpressions and misdiagnosed as \\ biphenotypic acute leukemia
}

\author{
Ayşen Türedi Yıldırım, Hüseyin Gülen
}

\section{ÖZET}

Bifenotipik akut lösemi (BAL), lösemik blastlarda aynı hücre üzerinde birden çok antijen ko-ekspresyonu varlığı veya iki farklı türde blast popülasyonu bulunması olarak tanımlanır. Burada öncelikle BAL tanısı alan, sonraki tetkiklerinde akut myelositer lösemi M1 (AML-M1) olduğu saptanan bir hasta sunuldu. Dört yaşında erkek hasta, iki aydır olan yüksek ateş, halsizlik, iştahsızlık ve kilo kaybı şikayeti ile başvurdu. Kemik iliği aspirasyonu incelemesinde \%96 L2 tipi blastlar saptandı ve flow-sitometride CD79a, CD56, CD5, CD13, CD33, ve MPO pozitifiliği gözlendi. Bu sonuçlar "European Group for the Immunological Characterization of Leukemias (EGIL)" sınıflamasına göre değerlendirildiğinde BAL tanısı düşünüldü. Steroid tedavisine cevap vermemesi üzerine, flowsitometri sonuçları "Dünya Sağlık Örgütü (WHO)"nun sınıflamasına göre tekrar değerlendirildi. BAL tanısı dışlandı ve AML M1 tanısı düşünüldü. Flowsitometrideki CD79a, CD56 ve CD5 pozitifliği ise ko-ekspresyon olarak değerlendirildi. AML tanısına yönelik verilen kemoterapiye dramatik olarak cevap verdi. Bu vaka BAL tanısında EGIL kriterlerinin kullanımının hatalı sonuçlara yol açabileceğini, WHO sınıflamasının kullanılmasının daha uygun olacağını vurgulamak amacıyla sunuldu.

Anahtar kelimeler: Bifenotipik akut lösemi, akut myelositer lösemi, ko-ekspresyon.

\section{GíRiş}

Lösemik blastlarda aynı hücre üzerinde bir türden daha çok antijen ko-ekspresyonu varlığı veya iki farklı türde blast popülasyonu bulunması bifenotipik akut lösemi olarak tanımlanır ve tüm lösemilerin \%2,5 ini oluşturur [1]. 1995 y1lında "European

\begin{abstract}
Biphenotypic acute leukemia (BAL) is defined as the existence of multiple antigen coexpression in leukemic blasts or two different types of blast population. In this study, a patient who was first diagnosed with BAL and later with acute myeloid leukemia M1 (AML-M1) is presented. The patient was four-year-old male and had complaints about high fever, fatigue, lack of appetite, and weight loss for two months. \% 96 L2 type blasts were identified in bone marrow aspiration, and positive values for CD79a, CD56, CD5, CD13, CD33, and MPO were observed in flow-cytometry. These findings, evaluated on the basis of "European Group for the Immunological Characterization of Leukemias (EGIL)" criteria, suggested BAL. As the steroid treatment returned no response, the flow-cytometry findings were reevaluated based on "World Health Organization (WHO)" criteria. BAL was excluded and AML M1 was considered as a diagnosis. The positive values for CD79a, CD56, and CD5 were evaluated as coexpression. Chemotherapy was given as AML treatment, and the dramatic response was reported. This case is presented to show that, using EGIL criteria to evaluate BAL may be misleading, and thus using WHO criteria to evaluate BAL may be more appropriate.
\end{abstract}

Key words: Biphenotypic acute leukemia, acute myeloid leukemia, coexpression.

Group for the Immunological Characterization of Leukemias (EGIL)" tarafından bifenotipik akut lösemiyi (BAL) tanımlamak için miyeloid, T lenfoid ve B lenfoid seriyi tanımlayan kriterler geliştirilmiştir. 2008 de ise Dünya Sağlık Örgütü (WHO) "bilineal akut lösemi" ve "bifenotipik akut lösemi" olarak adlandırılan grupları bir araya toplamış ve

Celal Bayar Üniversitesi, Tıp Fakültesi, Pediatrik Hematoloji Kliniği, Manisa, Türkiye

Yazışma Adresi /Correspondence: Ayşen Türedi Yıldırım,

Celal Bayar Üniversitesi, Tıp Fakültesi, Pediatrik Hematoloji Kliniği, Manisa, Türkiye Email: aysen_turedi@hotmail.com

Geliş Tarihi / Received: 24.12.2014, Kabul Tarihi / Accepted: 16.02.2015

Copyright @ Dicle Tıp Dergisi 2015, Her hakkı saklıdır / All rights reserved 
miks fenotipik akut lösemiler olarak adlandırmıştır. Aynı zamanda miyeloid, T lenfoid ve B lenfoid seriyi tanımlayan antijenik özellikleri de belirgin şekilde değiştirmiştir [2,3]. EGİL sınıflamasına göre gereksiz ve hatalı BAL tanıları konulabilmektedir. Bu olgu BAL'in çocuklarda oldukça nadir görülmesi nedeni ile, EGILL sinıflamasındaki yetersizliklere ve WHO sinıflaması ile arasındaki farklara dikkat çekmek amaciyla sunuldu.

\section{OLGU}

Dört yaşında erkek hasta, iki aydır ara ara olan yüksek ateş, halsizlik, iştahsızlık ve son iki ayda $3 \mathrm{~kg}$ kadar kilo kaybı şikayeti ile başvurdu. Özgeçmişinde özellik yoktu. Soygeçmişinde anneanne ve dedede mide CA olduğu öğrenildi. Fizik muayenesinde soluk görünümdeydi, karaciğer non-palpabl ve dalak kot altında iki cm palpabl idi. Laboratu-

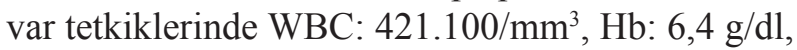
Plt: $44.000 / \mathrm{mm}^{3}$, LDH: $2188 \mathrm{U} / \mathrm{L}$, Ü. asit: $4,5 \mathrm{mg} /$ dl, K: 6,4 mEq/l, Na: $139 \mathrm{mEq} / 1, \mathrm{BUN}: 8,8 \mathrm{mg} / \mathrm{dl}$, Cr: $0,23 \mathrm{mg} / \mathrm{dl}$, Sedim: $86 \mathrm{~mm} / \mathrm{h}$ saptand1. Periferik yaymada \%95 blast, kemik iliği (Kİ) yaymasında ise \%96 L2 tipi blast (Şekil 1) saptand1. $\mathrm{NaHCO}_{3}$ içeren hidrasyon sıvısı ve allopürinol başlandı. Hiperpotasemiye yönelik salbutamol, Ca glukonat, insülin/glukoz infüzyonu tedavileri verildi ve izlemde hiperpotasemisi düzeldi. Flow-sitometri sonucunda CD34: \%78,5, CD117: \%34,3, CD33: \%82,1, CD13: \%69,6, MPO: \%30, CD5: \%22,2, sCD79a: \%49,1, CD56: \%40.5 saptand1. EGIL siniflamas1na göre CD79a: 2 puan, CD5: 1 puan olmak üzere lenfoid seriden 3 puan ald1. MPO: 2 puan, CD13: 1 puan, CD33: 1 puan olmak üzere myeloid seriden de 4 puan aldı. Her iki seriden 2 puanın üzerinde aldığ için bifenotipik akut lösemi tanısı düşünüldü.

Blastların L2 tipi görünümünde olması ve diğer klinik ve laboratuvar bulguları nedeni ile önce ALL tedavisi planlandi. Düşük doz $6 \mathrm{mg} / \mathrm{m}^{2}$ prednizolon tedavisi başlandı ve beş günde tam doza $(60 \mathrm{mg} /$ $\mathrm{m}^{2}$ ) çıkıldı. Tedaviye yanıt gözlenmemesi nedeni ile flowsitometri sonuçları WHO' nun BAL kriterlerine göre tekrar değerlendirildi. WHO'nun BAL kriterlerine uymaması ve patolojiye gönderilen preparatlarda da MPO'nun kuvvetli pozitif bulunması nedeni ile AML M1 düşünüldü. Lenfoid belirteçler olan CD 79a, CD5 ve CD56 pozitifliği ise ko-ekspresyon olarak yorumland1. WBC sayısı yüksek olduğu için hidroksiüre $(20 \mathrm{mg} / \mathrm{kg})$ ve düşük doz ara-c $(40 \mathrm{mg} /$ $\mathrm{m}^{2}$ ) başlandı. WBC sayısında yeterli düşme elde edilemeyince iki ünite ERT, iki ünite TDP ile iki kez exchange transfüzyon yapıld1. Exchange trans-

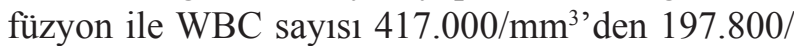
$\mathrm{mm}^{3}$ 'e düştü. Sonrasında BFM-AML 2004 protokolüne göre AIE (ARA-C, idarubisin ve etoposid) kemoterapisi başladı ve hastanın WBC sayısı sekiz günlük tedavinin sonunda 1800/mm3'e düştü. Bu tedaviler sirasında hastada tümör lizis sendromu ve hipervizkoziteye bağlı tromboz yada kanama gözlenmedi. Onbeşinci gün Kİ'nde \%3 blast görüldü ve remisyonda olarak değerlendirildi. Moleküler tetkiklerinde; $\mathrm{t}(8 ; 21), \mathrm{t}(15 ; 17)$ ve inversiyon 16 negatif bulundu.

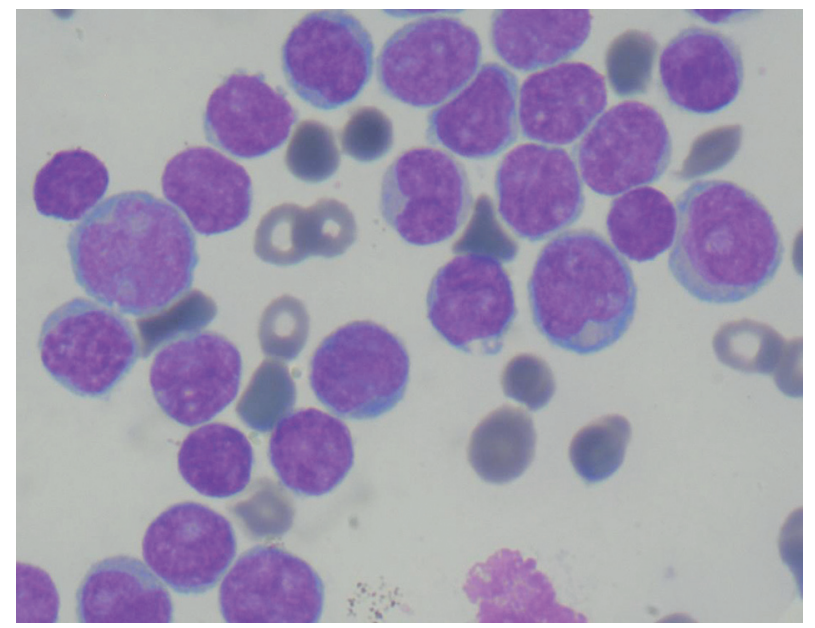

Şekil 1: Kemik iliği yayması

\section{TARTIŞMA}

Bifenotipik akut lösemi blastlarda aynı hücre üzerinde bir türden daha çok antijen ekspresyonu varl1ğ1 veya iki farklı türde blast popülasyonu bulunması olarak tanımlanır. Tüm akut lösemilerin 2\%-5\%'ini oluşturur. Miyeloid ve B hücre serilerini birlikte taşıyanlar olguların 47\%-72\%'sini oluştururken, miyeloid ve $\mathrm{T}$ hücre serilerini birlikte taşıyanlar $\% 24$ 'ünü oluşturur. $\mathrm{T}+\mathrm{B}$ hücre birlikteliği ve miyeloid $+\mathrm{T}+\mathrm{B}$ hücre birlikteliği ise çok daha nadirdir. Klinik belirtileri diğer akut lösemiler ile benzer özellik gösterir. Bununla birlikte ekstra-meduller infiltrasyon klasik akut miyelositer lösemi (AML) veya akut lenfositer lösemiye (ALL) göre daha fazla gözlenir [1,4]. 
1995 y1lında EGILL tarafından immünolojik s1nıflamaya dayalı BAL tanısı koyabilmek için skorlama sistemi geliştirilmiştir. Bu skorlama sisteminde $\mathrm{B}$ hücre, $\mathrm{T}$ hücre ve miyeloid hücre serilerine spesifik çeşitli immünolojik belirteçlere farklı puanlar tanımlanmıştır. CD3, CD22, CD79a, IgM, miyeloperoksidaz (MPO) ve T hücre reseptörü (TCR) nü içeren stoplazmik belirteçlere en yüksek puan olan 2 puan verilirken, daha az seri spesifik olanlara(CD2, CD5, CD8,CD10, CD13, CD19, CD20, CD33, CD65 ve CD117) 1 puan, diğer belirteçlere ise(CD1a, CD7, CD14, CD15, CD24, CD64 veTdT) 0,5 puan verilmiştir. Her iki seriden ( $\mathrm{T}$ hücre, B hücre veya miyeloid hücre serileri) 2'nin üzerinde puan alan hastalar BAL olarak tanımlanmıştır (Tablo 1)[2]. Zamanla EGİL sınıflamasının bazı kısıtlılıkları olduğu fark edilmiştir. İlk olarak EGİL de hücre serilerine spesifik belirteçler tam olarak tanımlanmamıştır. Bazı hücre serilerine spesifik belirteçlere yüksek puan verilmesine rağmen (CD3, CD22 ve MPO gibi), diğer seri spesifik belirteçlere daha düşük puan verilmiştir (CD7, CD13, CD19, CD20 ve CD33 gibi). EGİL sınıflamas1 CD79a'nın $\mathrm{B}$ hücreler için spesifik olduğunu söylemektedir. Fakat CD79a hem T hücrelerde hem de miyeloid hücrelerde sıklıkla ko-ekspresyon olarak bulunabilmekte ve yanlışlıkla BAL tanısına neden olabilmektedir [5]. Bir çalışmada AML tanısı olan 89 hastada flow-sitometri ile CD 79a çalışılmış, hastaların ikisinde kuvvetli pozitif bulunmuş ve AML M2 olan bu iki hastada $\mathrm{t}(8 ; 21)$ mutasyonu pozitif saptanmıştır [6]. Bir başka çalışmada ise 46 AML hastasında CD7, CD56 ve CD79a çalışılmış, hastaların 15'inde CD7, 10'unda CD56, dördünde ise CD79a ko-ekspresyon olarak pozitif bulunmuştur. CD79a pozitif olan bu dört hastanın tamamı akut miyeloblastik lösemi (AML M0, AML M1 ve AML M2) olan grupta saptanmıştır [7]. Bizim hastamızda ise CD79a ve CD56 ko-ekspresyonu ile birlikte CD5 ko-ekspresyonu da vardi.

Sitogenetik veriler açısından incelendiğinde EGIL siniflamasında sitogenetik veriler dikkate alınmamakta, sadece immünolojik belirteçler baz alınmaktadır. Çok iyi tanımlanmış bir AML yanlışlıkla BAL olarak tanı alabilmektedir. Bazı $\mathrm{t}(8 ; 21)$ (q22;q22) pozitif AML vakalarında B hücre belirteçleri ekspresyonu, bazı $\mathrm{t}(15 ; 17)(\mathrm{q} 22 ; \mathrm{q} 12)$ pozitif AML vakalarında $\mathrm{T}$ hücre belirteçleri ekspresyonu ve erişkin B ALL vakalarının \%23'ünde MPO ekspresyonu bildirilmiştir [4,5]. Bir diğer kısıtlılık ise BAL için optimal bir tedavi olmaması ve bu nedenle EGILL sinıflamasının sebep olduğu hatalı BAL tan1larının tedavide sıkıntılara yol açabilmesidir.

Tablo 1. EGIL e göre bifenotipik akut lösemi kriterleri [1]

\begin{tabular}{|c|c|c|c|}
\hline \multicolumn{3}{|c|}{ Puan B-hücre serisi T-hücre serisi } & \multirow{2}{*}{$\frac{\text { Miyeloid hücre seris }}{\text { Anti-MPO }}$} \\
\hline 2 & CD79a & CD3(cyt/m) & \\
\hline & Cyt lgM & Anti-TCR & \\
\hline & Cyt CD22 & Anti-TCR & \\
\hline \multirow[t]{4}{*}{1} & CD19 & CD2 & CD13 \\
\hline & CD10 & CD5 & CD33 \\
\hline & $\mathrm{Cd} 20$ & CD8 & CD65s \\
\hline & & CD10 & CD117 \\
\hline \multirow[t]{3}{*}{0,5} & TdT & TdT & CD14 \\
\hline & CD24 & CD7 & CD15 \\
\hline & & CD1a & CD64 \\
\hline
\end{tabular}

2008 y1lında BAL kriterleri WHO tarafından yeniden değerlendirilmiş ve miyeloid, B lenfoid ve $\mathrm{T}$ lenfoid komponentleri belirleyen kriterler önemli ölçüde değiştirilmiştir. Miyeloid hücreler için MPO, T hücreler için $\mathrm{CD} 3$ ve $\mathrm{B}$ hücreler için $\mathrm{CD} 19$ bulunmas1 zorunluluğu getirilmiştir (Tablo 2) [4]. Eskiden bilineal akut lösemi ve bifenotipik akut lösemi olarak tanımlanan grup "Ambiguous lineage (Belirsiz tür)" içinde tanımlanmış ve "Mikstfenotip akut lösemi (MPAL)" olarak isimlendirilmiştir. Bu hastalarda belirlenen majör sitogenetik anormallikler ( $\mathrm{t}(9: 22)$ veya MLL genini içine alan translokasyonlar) ek olarak değerlendirilmiş ve bunların dışında genelde spesifik bir genetik defektle sinıflandirılan lösemiler (t(8:21) gibi) MPAL kategorisine alınmamıştır [3].

Tablo 2. WHO ya göre bifenotipik akut lösemi kriterleri [4] MPO (flowsitometri, immunohistokimyasal

$\begin{array}{ll}\text { Miyeloid seri } & \begin{array}{l}\text { veya sitokimyasal) veya monositik belirteç- } \\ \text { lerden en az ikisi (NSE, CD11c, CD14,CD64, }\end{array}\end{array}$

$\begin{array}{ll}\text { Miyeloid seri } & \begin{array}{l}\text { veya sitokimyasal) veya monositik belirteç- } \\ \text { lerden en az ikisi (NSE, CD11c, CD14,CD64, }\end{array}\end{array}$ lizozim) Sitoplazmik CD3 veya Yüzeyel CD3 (mikst fenotipik akut lösemide nadirdir)

Güçlü CD19 ekspresyonu ve CD79a, sitoplazmik CD22, CD10 dan en az birinin güçlü B-lenfoid seri ekspresyonu veya Zayıf CD19 ekspresyonu ve CD79a, sitoplazmik CD22, CD10 dan en az ikisinin güçlü ekspresyonu 
Biz de öncelikli olarak hastamıda EGIL kriterlerine göre $\mathrm{T}+\mathrm{B}+\mathrm{M}$ seriyi içeren $\mathrm{BAL}$ tanıs1 düşünmüş ve kemik iliğindeki L2 tipi blastlarının görünümü, WBC yüksek olmasına rağmen belirgin ekstramedüller tutulum olmaması nedeni ile öncelikle ALL tedavisi vermiştik. Tedaviye cevap alınamaması nedeni ile WHO sinıflamasına göre hasta tekrar değerlendirildiğinde BAL tanısına uymadı $\breve{1}$ görüldü. Flow-sitomeri sonucuna göre minimal diferansiyasyonu olan AML (AML M1) tanıs1 alan hastada AML bazlı kemoterapiye dramatik yanıt alındı. AML M1 pediatrik AML' ler içinde oldukça nadirdir ve morfolojik olarak tanınması güçtür. $\mathrm{Bu}$ nedenle flowsitometri ile sitokimyasal boyamalar son derece önemlidir. Bu olgu nedeniyle flowsitometri sonuçlarının yorumlanmasındaki farklılıklara, sitokimyasal boyaların önemine ve indiferansiye AML gruplarının ve bifenotipik lösemilerin tanısındaki güçlüklere dikkat çekmeyi amaçladık.

Sonuç olarak, bifenotipik lösemi tanısında EGIL kriterleri hatalı BAL tanısına yol açabilmektedir. Bu nedenle BAL'dan şüphelenilen hastalarda
WHO sinıflamasının kullanılması daha uygun olacaktır.

\section{KAYNAKLAR}

1. Bene MC. Biphenotypic, bilineal, ambiguous or mixed lineage: strange leukemias! Haematologica 2009;94:891-893.

2. Bene MC, Castoldi G, Knapp W, et al. Proposals for the immunological classification of acute leukemias. European Group for the Immunological Characterization of Leukemias (EGIL). Leukemia 1995;9:1783-1786.

3. Vardiman JW, Thiele J, Arber DA, et al. The 2008 revision of the World Health Organization (WHO) classification of myeloid neoplasms and acute leukemia: rationale and important changes. Blood 2009;114:937-951.

4. Ye Z, Wang S. Mixed phenotype acute leukemia. Chin Med J 2014;127: 2999-3003.

5. Zhao XF, Gojo I, York T, et al. Diagnosis of biphenotypic acute leukemia: a paradigmatic approach. Int J Clin Exp Pathol 2009;3:75-86.

6. Kozlov I, Beason K, Yu C, Hughson M. CD79a expression in acute myeloid leukemia $t(8 ; 21)$ and the importance of cytogenetics in the diagnosis of leukemias with immunophenotypic ambiguity. Cancer Genet Cytogenet 2005;163:62-67.

7. Cruse JM, Lewis RE, Pierce S, et al. Aberrant expression of CD7, CD56, and CD79a antigens in acute myeloid leukemias. Exp Mol Pathol 2005;79:39-41. 